\title{
LA MÚSICA DE ROMA
}

Por Jorge Velazco

A RUBÉN BONIFAZ NUÑO

Quod vides perisse, perditum ducas

La música de la antigüedad está perdida para siempre. De los grandes monumentos artísticos de los antepasados remotos del siglo $\mathrm{xx}$, el de la música ha desaparecido al grado que ni siquiera perduran sus ruinas. Tan sólo vestigios, muchas veces inconexos o fragmentarios, y testimonios, muchas veces de personas sin conocimientos o interés, alcanzan a indicarnos el camino espléndido de la música del pasado.

$\mathrm{Y}$, sin embargo, el estudio, la práctica de la música en los pueblos antiguos, es tan fascinante como cualesquiera de los múltiples aspectos conocidos de su vida diaria. Aún más, pues la cultura musical es el área general de comunicación humana, ya que no depende del conocimiento del lenguaje hablado para su recepción y comprensión, y sus instituciones se dirigen al intelecto a través de la emotividad, que puede suponerse un elemento común y básicamente similar en todo ser humano.

Roma, a través de su fascinadora evolución histórica, produjo música que ha muerto a un grado casi absoluto. Nuestros amados padres, los romanos, influidos por nuestros venerados abuelos, los griegos, y proclives a la influencia etrusca y oriental, desarrollaron un arte musical cuyo rastro visible se ha perdido pero que se halla presente en toda nuestra música, a través de la herencia que legaron a toda nuestra civilización. El hecho de que no podamos reconocer distintamente los elementos romanos ${ }^{1}$ y los diversos de ellos en nuestra música, tan sólo prueba que la música no es mosaico sino fusión vital y que el grado de absorción propia del arte sonoro permite la incorporación completa de dispares elementos. Los primitivos cristianos, aun romanos, y los cantores del pueblo, recibieron la música de Roma - no había otra- que llevaba en sí, como un crisol, las síntesis griega, egipcia, asiria, caldea, etrusca, fenicia, siria e incluso la escita y la púnica.

No hay que olvidar la gran dificultad de hablar sobre música romana

I Se dice que este tema cantado en la región de Auvernia, desde siempre, es una canción que las tropas de César entonaban en la Galia y que fue recibida y adop. tada por el pueblo La letra, de gran antigüedad, sugiere remotas conexiones con lá religión romana diaria, que al pasar a la Edad Media se convirtió en oculto y misterioso rito (figura 1 ). 
en general. En primer lugar, la totalidad del material de estudio conocido se refiere a los instrumentos, a las circunstancias profesionales de los músicos o al papel de la música en diversas situaciones; pero carecemos por completo de fuentes de información sobre la música misma. Por otra parte, no es lícito hablar del largo periodo romano, que cubrió muchos siglos y acogió muchas influencias a la par que generaba otras, tomando una posición simplista o excesivamente generalizadora. La necesidad del trabajo de expertos en el mundo romano y de arqueólogos vuelven aún más difícil a este tipo de juicios ya que, es bien sabido, no es posible aplicar el mismo criterio de interpretación que se usa en un determinado periodo del mundo grecorromano a su integridad, que lo válido para una época puede no serlo para otra y que la distinción entre lo que es propiamente griego y lo romano en materias artísticas no puede ser establecida rígidamente.

La idea de que la música romana fue una de absoluta monodía que no conoció la armonía o el menor elemento polifónico es una concepción tan rígida y limitada que debe desecharse sin más, sobre todo por el hecho de estar basada en un supuesto imaginativo y no en datos fidedignos acerca de la música en sí que es desconocida para nosotros. Pese a todo, es claro que tres grandes influencias operaron sobre Roma. La primera fue aquella de los etruscos, la segunda vino de Grecia, y la tercera, no la menos importante, llegó del Oriente. Roma no sólo recibió estas influencias sino que adoptó, mezcló y desarrolló lo que sus pueblos afluentes le llevaxon. Entre ello estaban instrumentos musicales y música que se integraron, como sólo la música puede hacerlo, a la vida romana que tenía, como todo pueblo ha tenido, sus propias instituciones musicales. Habia música de características propias, que se componia especialmente para la comedia latina. Las canciones y los toques del ejército romano eran de origen nativo. Los "cantos de la antigua Roma" se habían cantado - según Catón el Viejo- al son de la tibia en los banquetes, a pesar de que en la época de Cicerón habían desaparecido. En la música popular del Imperio es teóricamente posible separar la raiz latina de las tradiciones griegas.

\section{Música y músicos}

Ya desde los tiempos arcaicos de Roma se tienen vestigios musicales. La severidad del primer mundo romano se reflejó en la idea de que la ostentación musical de los extranjeros conducía a la relajación de la 
moral por la vía del afeminamiento En el siglo v a. C. la Ley de las Doce Tablas prohibió llevar más de diez flautistas a un funeral. Todavia en el 115 a. C. hubo una ley que imponía la actuación del músico latino en Roma. La expansión romana dejó entrar a la influencia extranjera con su nueva, música y la primera que se recibió fue la de los músicos griegos. ${ }^{2}$ El comercio trajo nuevas modas, condicionó la demanda de lujos y admitió la presencia en Roma de grupos extranjeros que conservaban su identidad nacional, practicaban sus propias costumbres religiosas y tocaban su propia música. Las nuevas religiones fueron primero perseguidas, luego toleradas y finalmente practicadas por diversos emperadores en diferentes épocas. La Segunda Guerra Púnica trajo el culto a Cibeles, la Gran Madre, que provenía de Frigia y llegó a Roma en el 204 a. C. Los ciudadanos romanos tenían prohibido vestir la túnica ceremonial o tomar parte en las ceremonias del culto, pero los instrumentos musicales -y, presumiblemente, la música- fueron rápidamente adoptados por los romanos. Platillos, pandereta y flautas de Cibeles aparecen en pintuxas, relieves y textos. La flauta Berecintia con su corno curvo (inflexo Berecyntia tibia cornu), la flauta demente (furiosa tibia) y los tambores bajos (inania tympana). Las flautas extranjeras eran más poderosas que las gemelas corrientes y las eclip. saron parcialmente, si bien la fuerte tradición de los primitivos aulos permaneció viva hasta el fin del Imperio. En el Museo Capitolino se conservan diversas piezas escultóricas que retratan instrumentos musicales, tanto autóctonos como adoptados (figura 2).

Durante el Imperio, los recitales musicales se volvieron muy populares. La costumbre griega de cantar acompañándose de una kithara -ampliamente extendida en el Ática y el Peloponeso, y conocida en cierto grado en Roma y las provincias occidentales- resultó una intrusión en las costumbres romanas y no fue completamente adoptada a pesar de la intensa actividad de los maestros griegos y del apoyo de varios emperadores -entre los que destaca Nerón, quien era un virtuoso frustrado que desempeñaba el empleo de emperador de Roma.

2 La absorción debe haber tenido algunas dificultades ya que Polibio relata una historia sobre la incomprensión del arte de algunos músicos griegos que tocaron en Roma, en el 167 a $\mathbf{C}_{\text {. }}$, y que fueron escarnecidos por el público y obligados a suspender su concierto e improvisar un espectáculo más acorde con el gusto romano. $\mathrm{Si}$ bien algunas objeciones a la música extranjera, como la que Juvenal hizo contra los orontes sirios, pueden estar más relacionados con la reacción inmunológica nacionalista ( $y$, por ende, con una esfera sociopolitica) que con el disgusto por esa forma de arte. 
Durante el imperio de Adriano hubo un pasajero furor por la música griega en su corte, que dio grandes ventajas a Mesomedes, pero antes y después de ese periodo (corto por cierto) el compositor no tuvo, ni aspiró a tener, categoria de consagrado o clásico. El músico por excelencia, alrededor de cuya actividad estaba centrado el arte musical romano, era el ejecutante, que a veces componía su propia música pero subordinándola siempre a su papel de intérprete (figura 3).

Los virtuosos capturaron el interés y el corazón de los romanos del Imperio, tal vez a causa de su cercanía con la actividad circense y la consecuente afición romana. Los solistas virtuosos de moda en Roma eran adorados por la plebe, tenían un ardiente público que los reclamaba, se les pagaban sumas fabulosas por sus actuaciones y se les permitían toda clase de pataletas y extravagancias en su conducta, dentro y fuera del escenario. Estos virtuosos eran músicos itinerantes, tal vez por la imposibilidad de permanecer laxgo tiempo en un mismo lugar que tal actividad trae implicada; se agruparon en uniones profesionales a la manera de los comerciantes y llegaron a ejercer un monopolio casi absoluto hacia el siglo II d. C. Al virtuoso se le rendían honores, se le otorgaba la ciudadanía honoraria y se le erigian estatuas. Vespasiano pagó 400,000 sestercios al actor trágico Apolinaris, quien actuó en la reapertura del Teatro de Marcelo, acompañado por dos citharoedi (ejecutantes de cítara) que recibieron 200,000 sestercios por su actuación. Dos inscripciones de Afrodisias (Asia Menor) dan testimonio de un premio de 3,250 denarii pagados al primer citharoedus de un concurso. Ignoramos casi todo acerca del estilo de ejecución de tales estrellas. Lo más que se conoce es la fuerza y duración con que eran capaces de tocar o cantar, pero se podría aseverar que debe haber existido un nivel de ejecución elevado, tanto artística como técnicamente, pues la competencia era fuerte $y$ las claques, verdaderas instituciones, no aceptaban cubrir a ejecutantes débiles o incapaces de conmover a la muchedumbre. Algunas piezas eran tan bien conocidas por la multitud que se las tarareaba en las calles.

En la época de Augusto un collegium symphoniacorum que se ocupaba de ofrecer servicios religiosos públicos en Roma fue reconocido por el Senado como una asociación legítima, mediante un decreto especial. En Grecia, uniones locales de este tipo terminaron fusionándose en un "sagrado sínodo ecuménico de artistas al servicio de Dionisios"; pero los griegos no aceptaron a los músicos como clase social elevada, a pesar del majestuoso título de la liga musical y de los altos salarios que deven- 
gaban. Los maestros de retórica y gramática y los médicos tenían una posición social más elevada que la de los músicos. En Roma, esta situación fue casi idéntica a la griega, con algunas variantes en cuanto a los salarios de los maestros.

Los maestros de música existian como profesionales, y se sabe que en el siglo II $a$ " C. en una escuela elemental de Teos, en el Asia Menor, se pagaron de 500 a 600 dracmas anuales a profesores de lectura y escritura; 500 dracmas a profesores de gimnasia, y 700 a un maestro de música. La situación personal de estos profesionales puede haber influido en los salarios, pero, en todo caso, la situación no podría haber violentado notablemente las costumbres sociales generales. Los deberes de este maestro eran dar instrucción en música y enseñar a tocar la kithara tanto con plectrum como con los dedos, no se sabe de flautas u otros instrumentos, y algunos niños recibían únicamente la instrucción teórica, aparte del hecho de que no todos los niños de la escuela asistían a la clase de música. Habia un examen final y la importancia del sueldo asignado da una idea del lugar social de la música, ya que el salario normal de un artesano reputado era de un dracma diario y un médico no ganaba más de 1,000 dracmas al año.

Existe un papiro hallado en Alejandría, que data del 13 a. $\mathrm{C}_{\text {。 }}$ y que contiene un contrato de aprendizaje y enseñanza entre el dueño de un esclavo (el alumno) y un maestro de música. El papiro es fragmentario y algunos de sus términos técnicos no han sido completamente descifrados, pero se refiere al aprendizaje del joven esclavo; dice que debía enseñársele a tocar diversas melodías en varios instrumentos específicos y que debía ser capaz de acompañarse a sí mismo y a otros ejecutantes. El pago era de 100 dracmas y se liquidaría en dos exhibiciones. El término del contrato era de un año y al final del mismo el esclavo debía ser examinado por un jurado de tres músicos nombrado por el dueño para certificar su avance.

La enseñanza pudo haber sido de oído, ya que no se conoce hasta la fecha sistema romano de notación musical. Además, todos los testimonios gráficos de músicos los representan tocando de oído o de memoria, y no se conoce pintura, relieve o escultura que presente músicos leyendo al tocar. Mientras no se haga un descubrimiento que pueda desvirtuar esta conclusión podemos pensar que el alumno aprendía viendo al maestro y siguiendo sus consejos prácticos, ya que no parece que haya existido texto alguno para aprender música. En todo caso el sistema de notación musical romano es desconocido y si existió debe haber sido algún conoci- 
miento críptico y mágico reservado a los miembros de un cerrado grupo profesional que se perdió con la muerte de ellos.

Los músicos ocuparon un lugar privilegiado dentro de los trabajadores de la sociedad romana. Numa, sucesor de Rómulo y primer rey de Roma, dividió al pueblo romano en una serie de gremios y en su lista aparecen, en primer lugar, los flautistas. Cuando los flautistas sagrados se ponian en huelga (lo hicieron una vez) el Estado se alarmaba y los sobornaba para que volvieran al trabajo. Un flautista estaba usualmente presente y cerca del altar durante los sacrificios, si bien su presencia podría haber estado relacionada con la necesidad de cubrir algún eventual sonido desagradable proveniente de la víctima. Posteriormente, en las entradas triunfales y en las procesiones imperiales los músicos estaban presentes y en los primeros lugares (por razón de oficio más que por su poder o fuerza), y se ve siempre a un ejecutante de tuba cerca del emperador en los momentos más brillantes de la vida oficial. El sabio uso de la música para estimular o calmar a una muchedumbre fue conocido y abundantemente empleado en el mundo antiguo. La Ieyenda de Jericó es tan sólo uno de muy numerosos ejemplos.

Ya desde el siglo vi a. C. se dio situación social a los ejecutantes de tuba y cornu, al nombrarlos una clase oficial dentro de los ciudadanos romanos; el orden de precedencia fue: ejecutantes de tuba, de cornu y al final, algo despreciados y fuera de la lista de clases ciudadanas, ejecutantes de bucina. Se organizaban en ligas y gremios que tenían rígidas condiciones de ingreso y otorgaban acceso a sistemas de seguridad social. Ya en el siglo IIr a. C. cuando alguien ingresaba en uno de estos gremios, hacía un pago de 750 denarii al fondo común, y si moría o se jubilaba, o era degradado en su rango o admitido al ejército o tenía que hacer un viaje por mar, él o sus herederos recibían diversas sumas de dinero.

\section{Los instrumentos}

Nuestro campo más amplio del conocimiento de la música romana es el de los instrumentos musicales. Éstos eran completos y complicados, capaces de lograr una gran sonoridad y, a pesar de que la voz humana debe haber retenido el primer lugar en la consideración general, el uso de la música instrumental y el papel de los instrumentos parece haber sido más amplio e importante que en Grecia.

La tuba era larga, recta y fabricada usualmente de bronce, si bien hubo ejemplares de hierro y de madera con cuero. Estaba compuesta de sec- 
ciones que se acoplaban unas con otras y su longitud usual exa de $130 \mathrm{~cm}$. El instrumento era cilíndrico hasta casi su extremo, donde abruptamente se abría para formar la campana. El tudel era cónico, sustituible, y determinaba la calidad de la nota producida. Se usaba con frecuencia una banda de tela para mantener la boquilla estrechamente pegada a los labios al tocar, atada a un pequeño lazo cerca de la campana. Tal vez puedan ser obtenidos unos siete armónicos del instrumento que es bastante difícil tocar. Su origen es etrusco y era básicamente un instrumento militar.

El $\operatorname{salpinx}$ griego es el símil de la $t u b a$, pero era más corto, su campana más amplia y se usaba fuera del ejército como instrumento solista en concursos musicales.

Otro instrumento de origen etrusco y que se usó al principio en actividades militares era el cornu. Era cónico y se curvaba en más de la mitad de un círculo. Estaba hecho de bronce y en sus orígenes fue fabricado en cuerno. Tenía una barra de soporte que le permitía ser cargado sobre el hombro del ejecutante mientras que la campana colgaba sobre su cabeza en la misma dirección del rostro. Tenía una boquila separable, más larga que la de la tuba (figura 4).

Un instrumento críptico, confundido en la época romana y en la actualidad con el cornu, era la bucina. El ejecutante de la bucina, el bucinator era muy severamente distinguido de los cornicen. No se conoce representación alguna de una bucina, pero se sabe que la condición social del bucinator era inferior y subordinada. En diversos ataúdes de los cornicines está esculpido el cornu, pero el bucinator no aparece nunca con su bucina. Las descripciones son algo contradictorias, pero parece haberse originado en un cuerno de animal para llegar después a la construcción metálica. Se le asociaba con los plebeyos campesinos y se usaba en el ejército para señales rutinarias fuera del campo de batalla, donde la tuba y el cornu eran los únicos suficientemente poderosos para hacerse oír en el fragor de la lucha (figura 5).

El lituus proviene de la Etruria y era un cuerno natural con una gran extensión recta formada por un tubo metálico y una boquilla muy larga. En el Museo Vaticano hay un lituus de $140 \mathrm{~cm}$ hallado en Caere, que produce seis notas y está afinado en Sol. Otro lituus, hallado en el Rhin, cerca de Düsseldorf, está afinado en La. Su sonido es el de una trompeta de suave voz y era usado por el ejército en ocasiones ceremoniales.

Ya desde la cuarta dinastía, en el siglo xxvi a. C., aparecen flautas de 
lengüeta en Egipto, directas antepasadas del aulos griego y la tibia romana. Se decía que el giglaros griego era una especie egipcia de aulos.

El aulos griego, que era la tibia romana, es un instrumento de lengüeta ampliamente difundido por todo el mundo antiguo $\mathrm{y}$, principalmente, en la zona del Mediterráneo Oriental. Casi invariablemente se usaba en

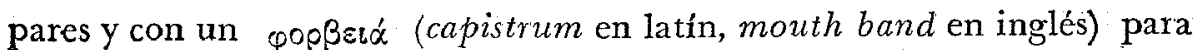
mantener fijos ambos instrumentos en la boca y ayudar a lograr una presión constante en la columna de aire Las flautas cortas de tres a cuatro agujeros eran conocidas desde los más antiguos tiempos romanos. Hacia el final de la República y durante los primeros tiempos del Imperio las flautas fueron alargadas y llegaron a tener $60 \mathrm{~cm}$ y hasta quince agujeros. Se desarrollaron artificios mecánicos para cubrir algunos agu jeros. La flauta trasversa sencilla existió, pero su difusión fue muy limitada y su uso poco frecuente.

La tibia succentiva (izquierda) se sostenia a un nivel más bajo que la: incentiva (derecha); podría ser que el estilo hubiera pedido una respuesta de una a la otra, además de la posibilidad de tocar ambas simultáneamente (figura 6).

Las flautas frigias que la Magna Mater llevó a Roma eran muy poderosas y salieron pronto del rito religioso al dominio popular; una flauta era recta y la otra terminaba en una gran campana curva. Ya fueran las clásicas o las extranjeras adaptadas, las tibiae existieron como compañeras constantes de la vida musical del Imperio.

Virgilio describe un instrumento que sólo puede ser el utricularius, o ascaules. Su nombre más aproximado es el de "gaita" en castellano y resulta difícil identificar las referencias al instrumento en varios textos, a causa de que la palabra ûtrichulariais está asociada con un vinatero más que con un músico.

El órgano, que fue inventado en Alejandría en el siglo IIr a. C. se convirtió en un instrumento muy importante durante el Imperio. Atribuido a Hero de Alejandría (c. 150 d. C.), investigaciones recientes parecen indicar que su inventor fue Ctesibius (c. 246-221 a. C.), hijo de un barbero, quien vivía en el barrio de Aspendia. El hydraulus, tal como fue llamado el órgano romano de presión hidráulica, aparece en las fuentes literarias con profusión, pero no en forma analítica, así como en modelos de terracota y en diversos mosaicos. Dos hydrauli fueron desenterrados de Pompeya y en Aquincum se hallaron los restos de un hydraulus entre los escombros de una cava en la cual, según dicen los arqueólogos, caýó desde un salón de fiestas a causa de un incendio. El instrumento tiene 
DOI: http://dx.doi.org/10.22201/iie.18703062e.1977.47.1082

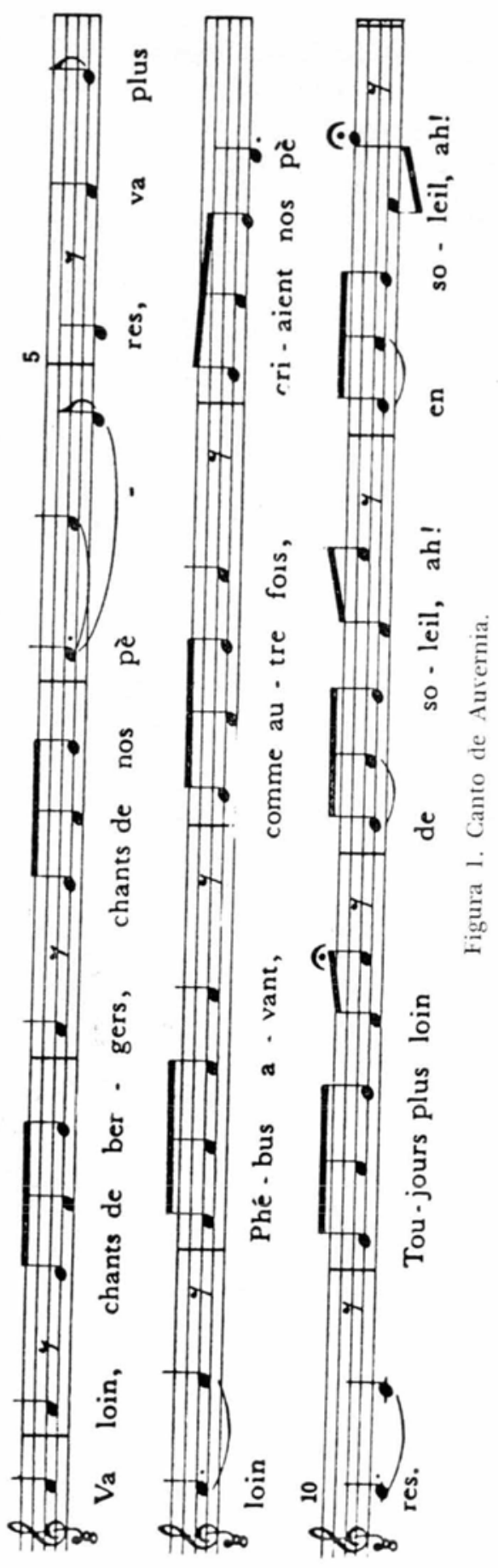


DOI: http://dx.doi.org/10.22201/iie.18703062e.1977.47.1082

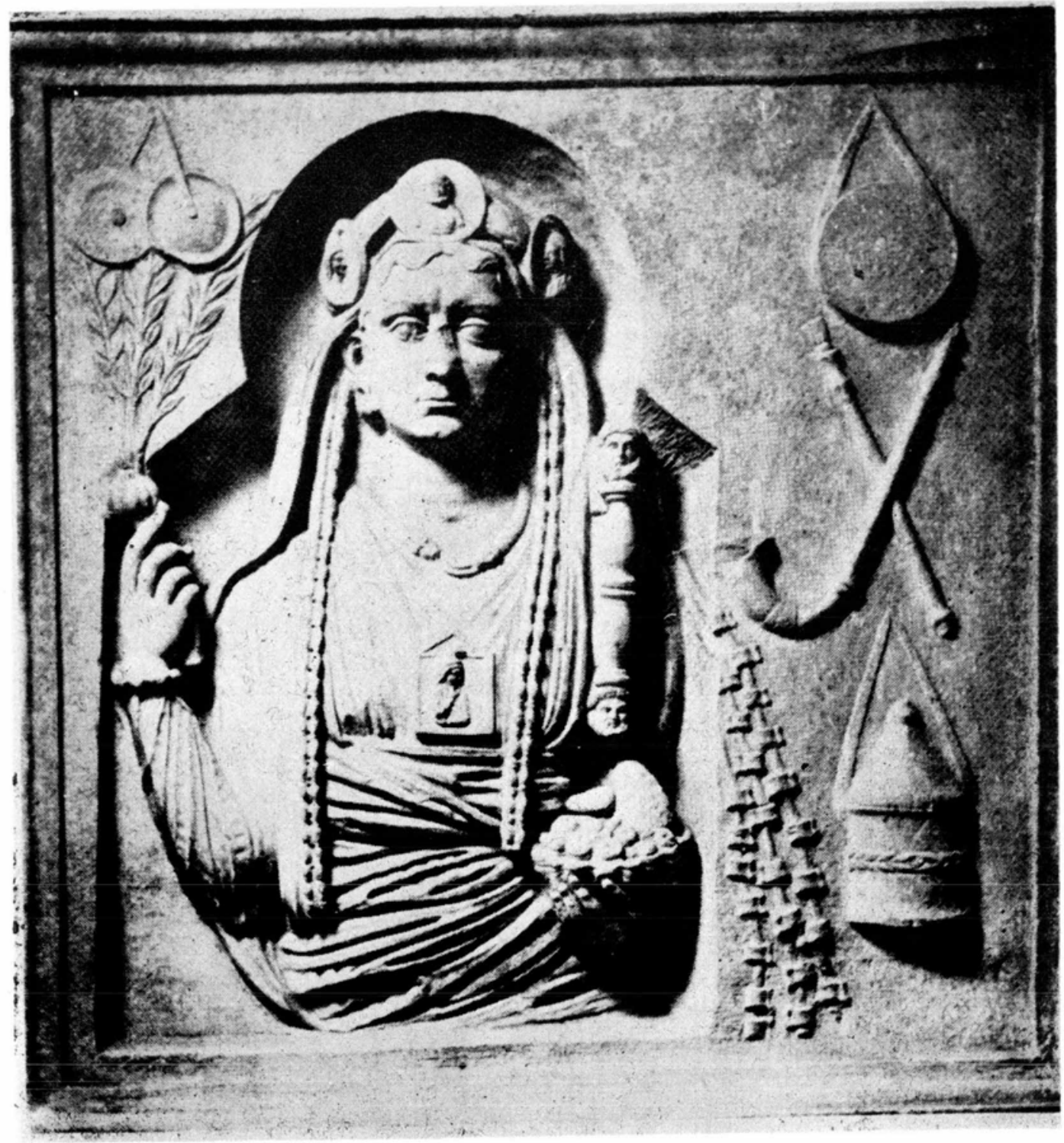

Figura 2. Sacerdote del culto de Cibeles. En el relieve aparecen platillos, tympanum y tibiae frigias (c. 150 a. C.) 


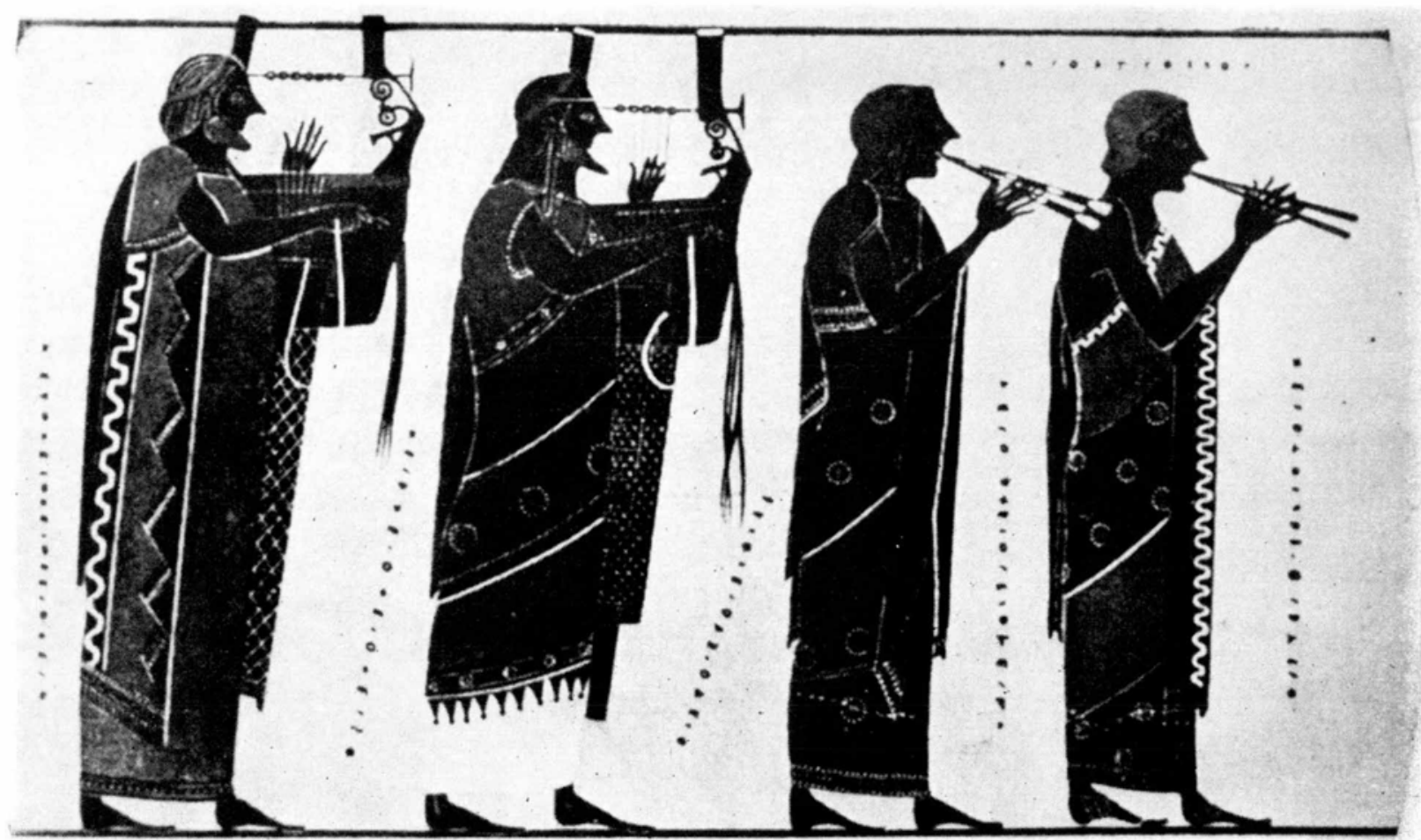

Figura 3. Intérpretes griegos de Kithara y aulos. Cerámica del Museo de Berlín. 
DOI: http://dx.doi.org/10.22201/iie.18703062e.1977.47.1082

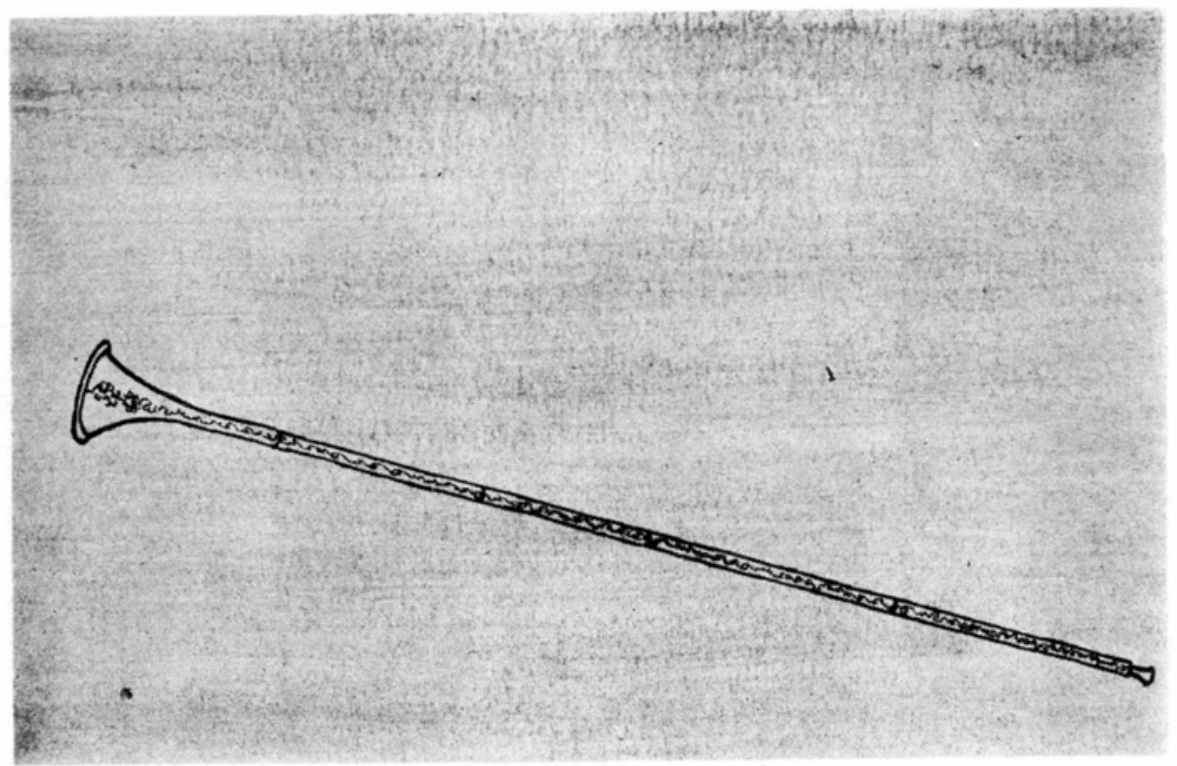

Figura 4. Tuba. 
DOI: http://dx.doi.org/10.22201/iie.18703062e.1977.47.1082

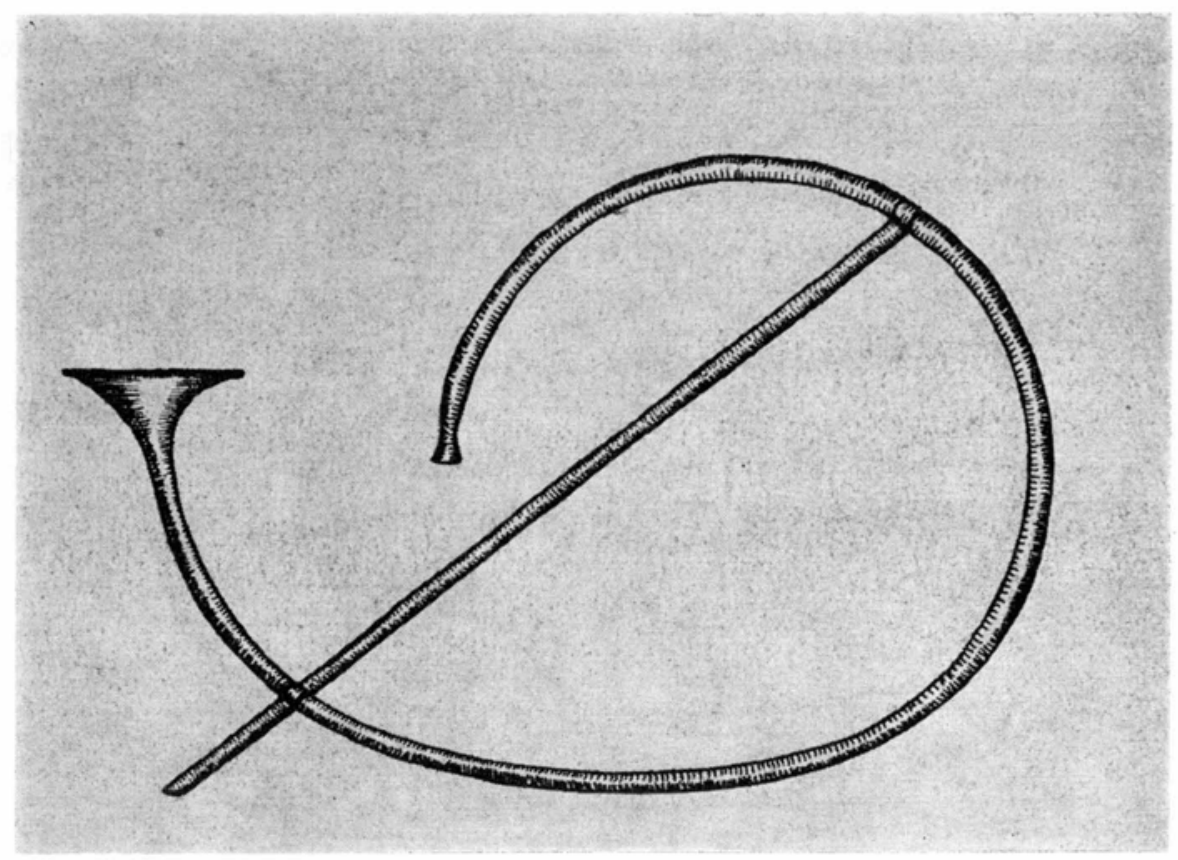

Figura 5. Cornu. 
DOI: http://dx.doi.org/10.22201/iie.18703062e.1977.47.1082

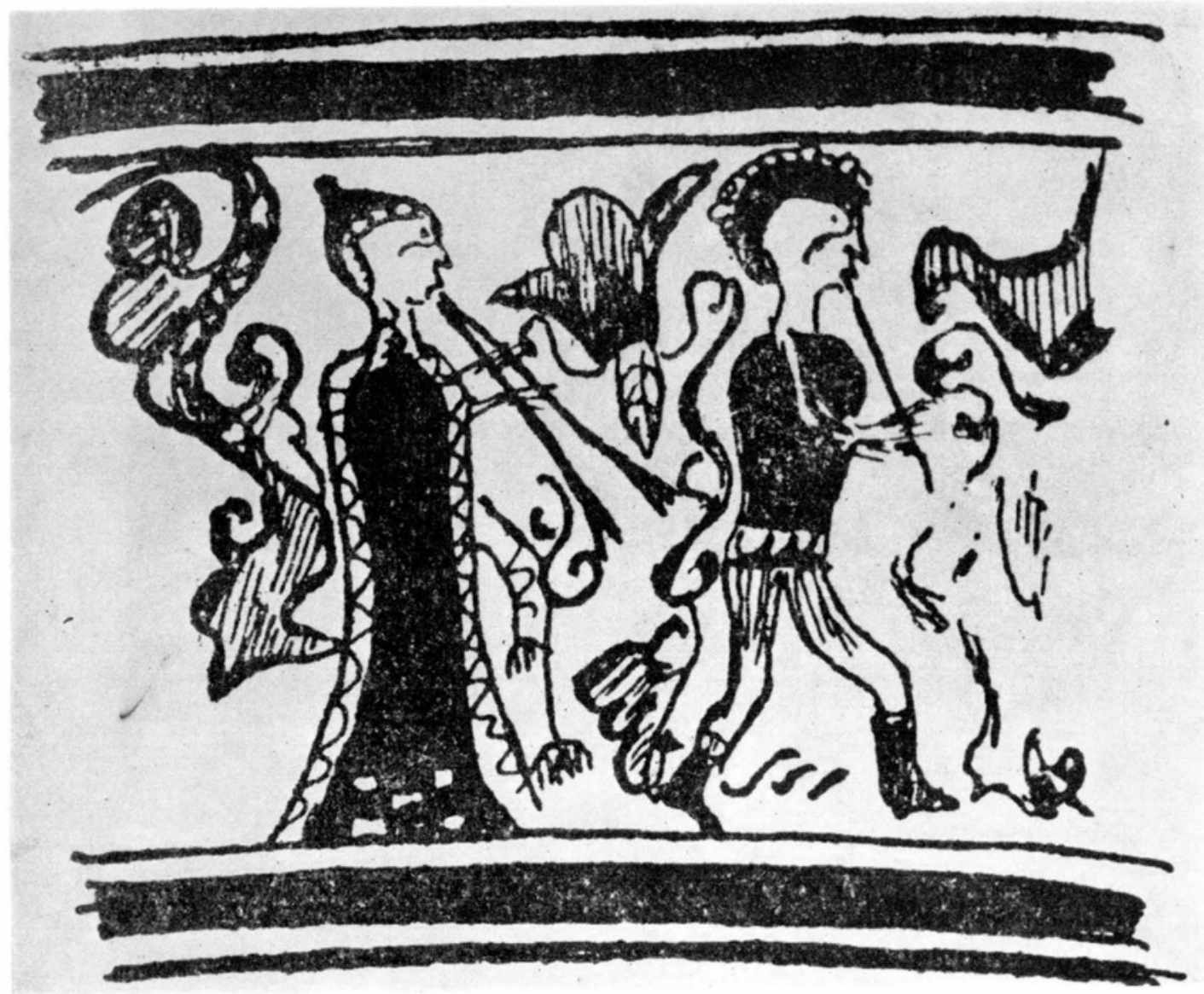

Figura 6. Mujer con aulos (cerámica ibera de Liria). 
DOI: http://dx.doi.org/10.22201/iie.18703062e.1977.47.1082

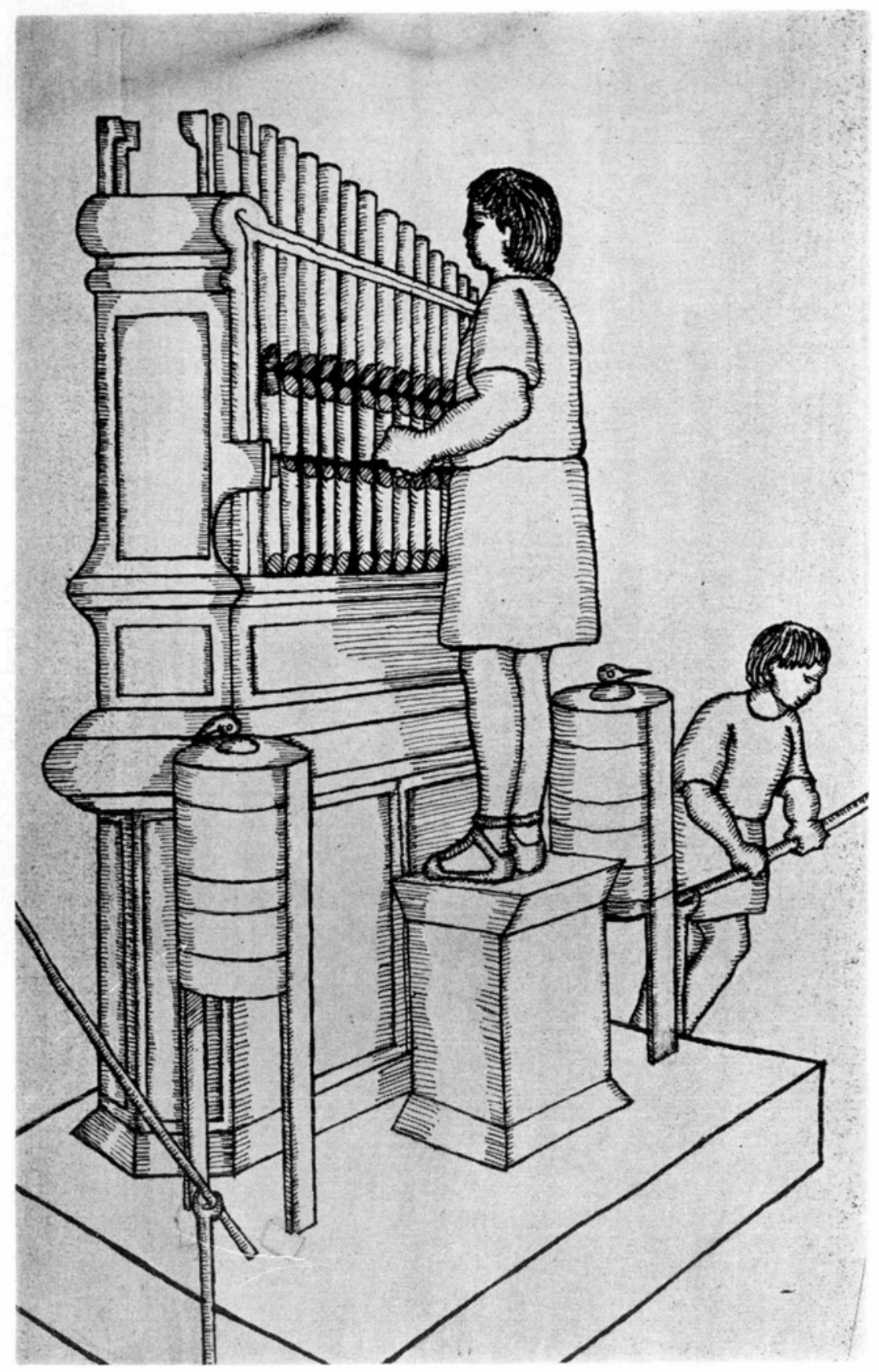

Figura 7. Hydraulus. 
DOI: http://dx.doi.org/10.22201/iie.18703062e.1977.47.1082

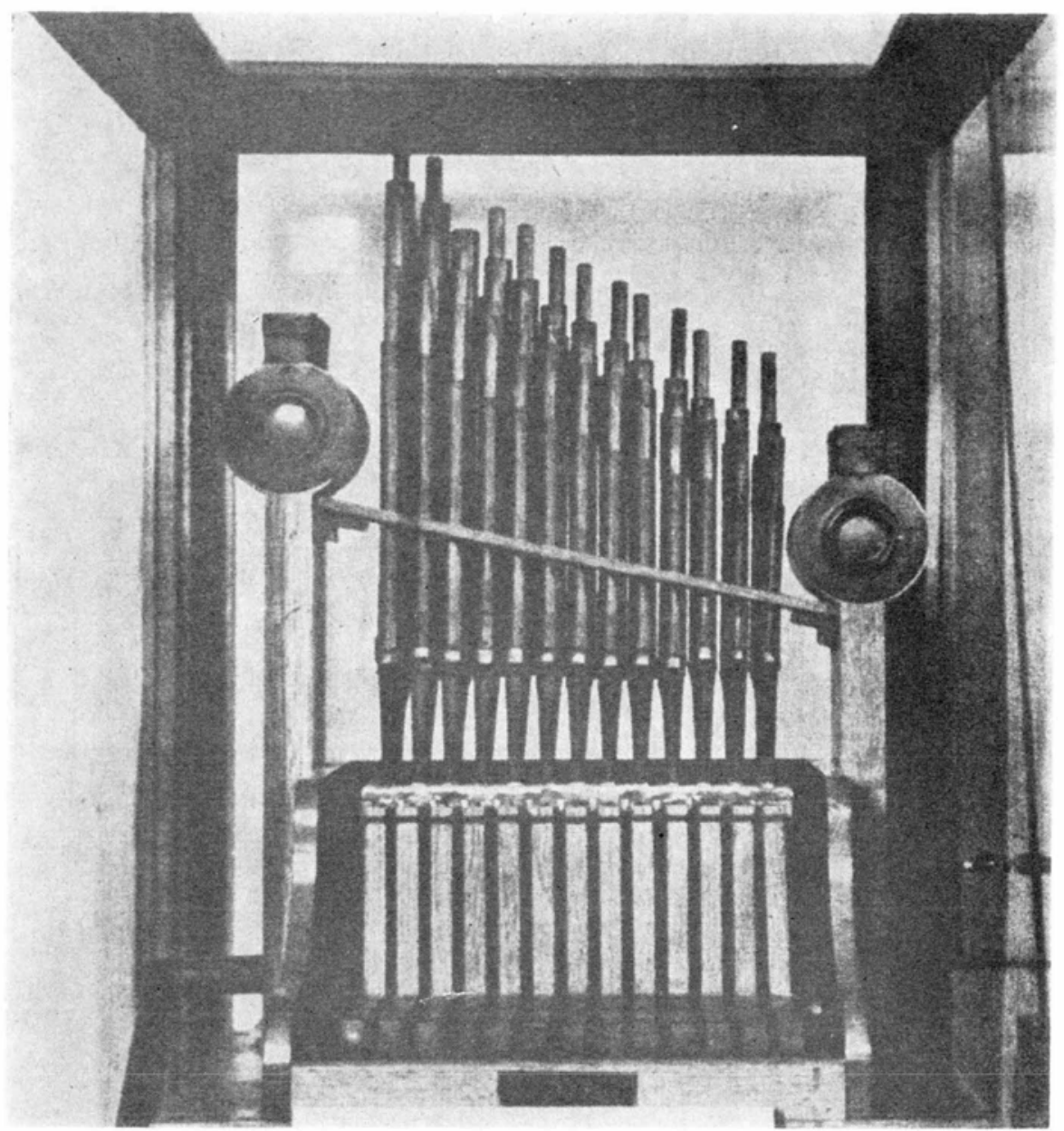

Figura 8. Reconstrucción del hydraulus de Aquincum. 
DOI: http://dx.doi.org/10.22201/iie.18703062e.1977.47.1082

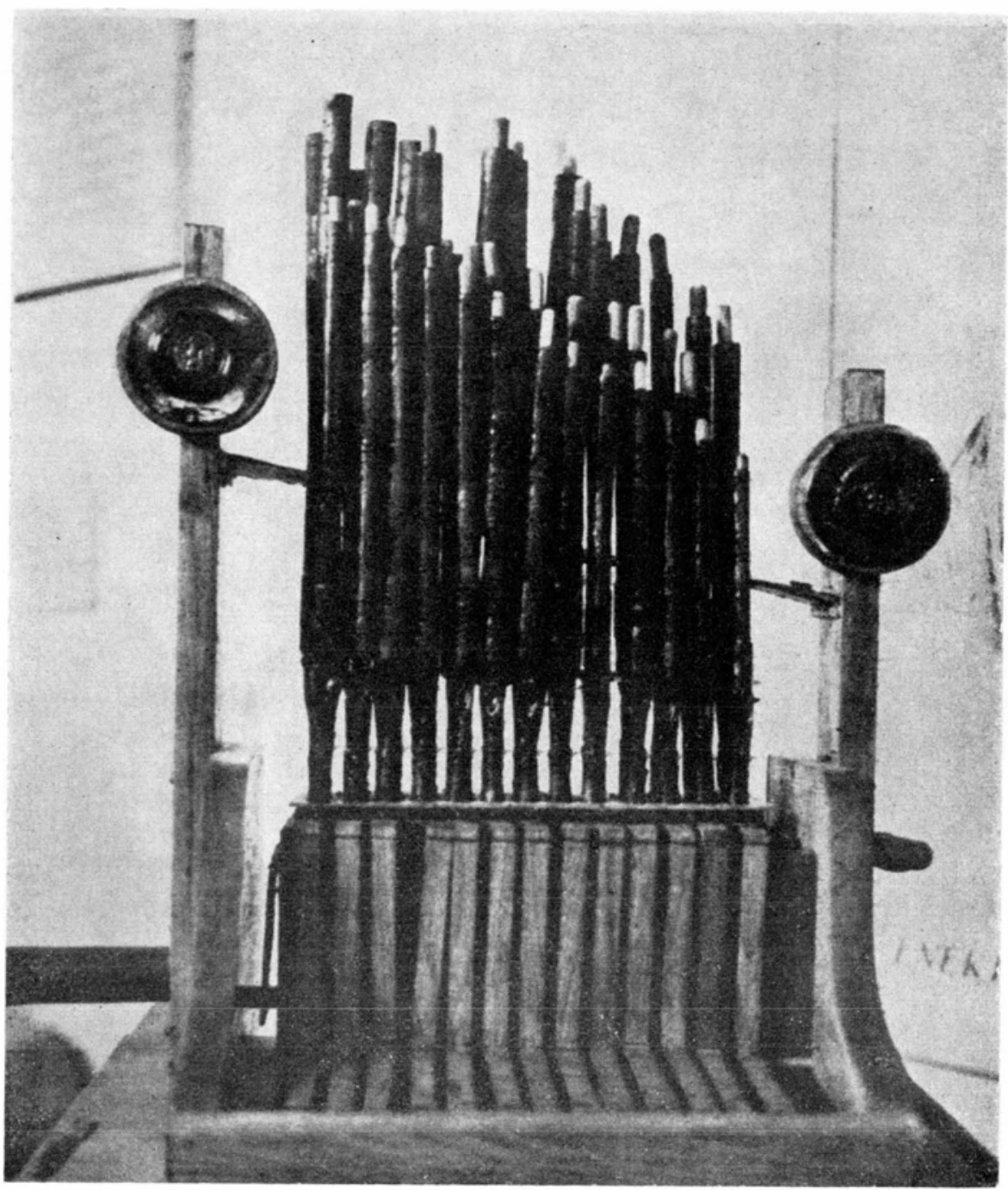

Figura 9. El hydraulus de Aquincum. 
DOI: http://dx.doi.org/10.22201/iie.18703062e.1977.47.1082

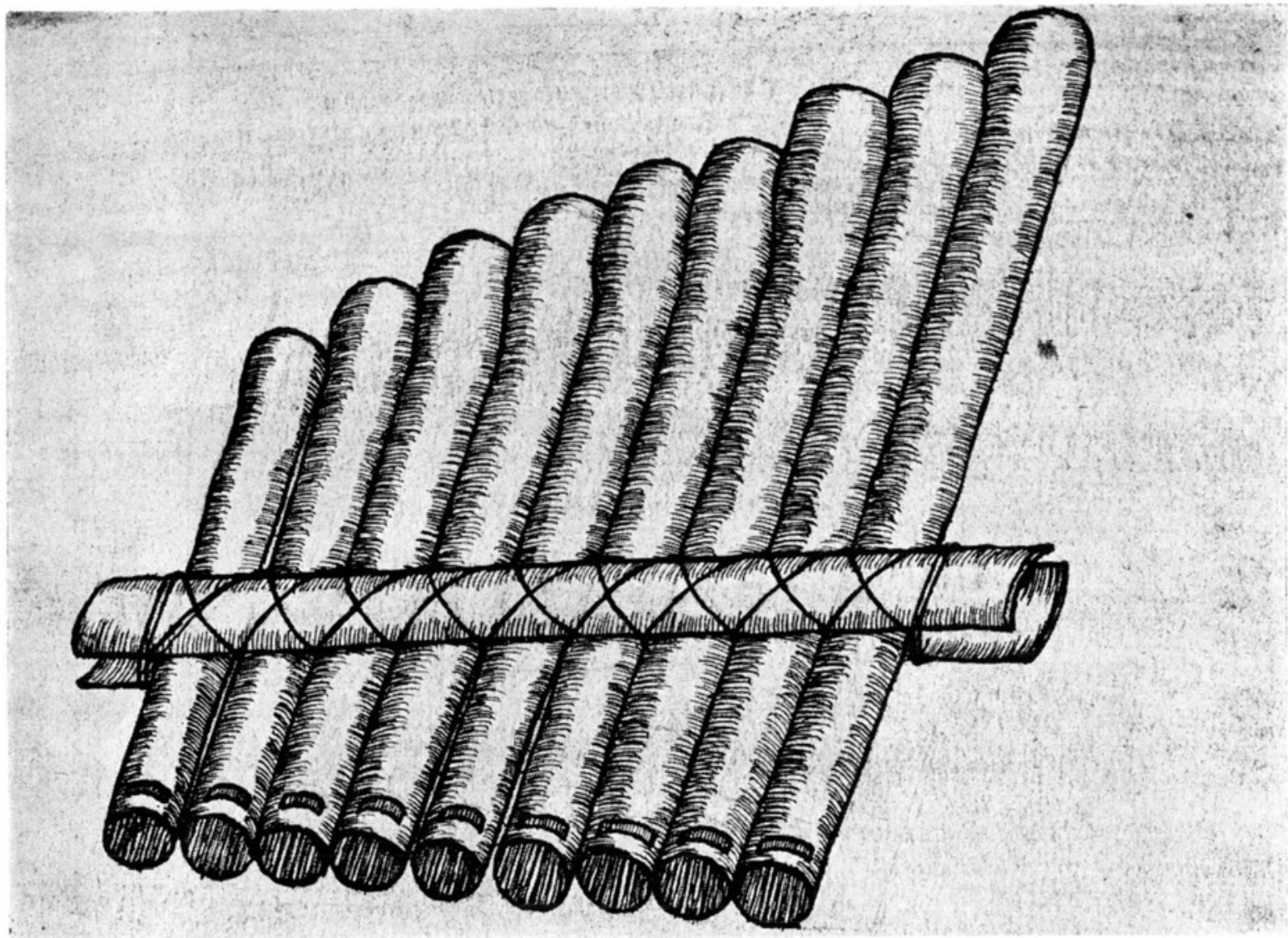

Figura 10. Syrinx. 
DOI: http://dx.doi.org/10.22201/iie.18703062e.1977.47.1082

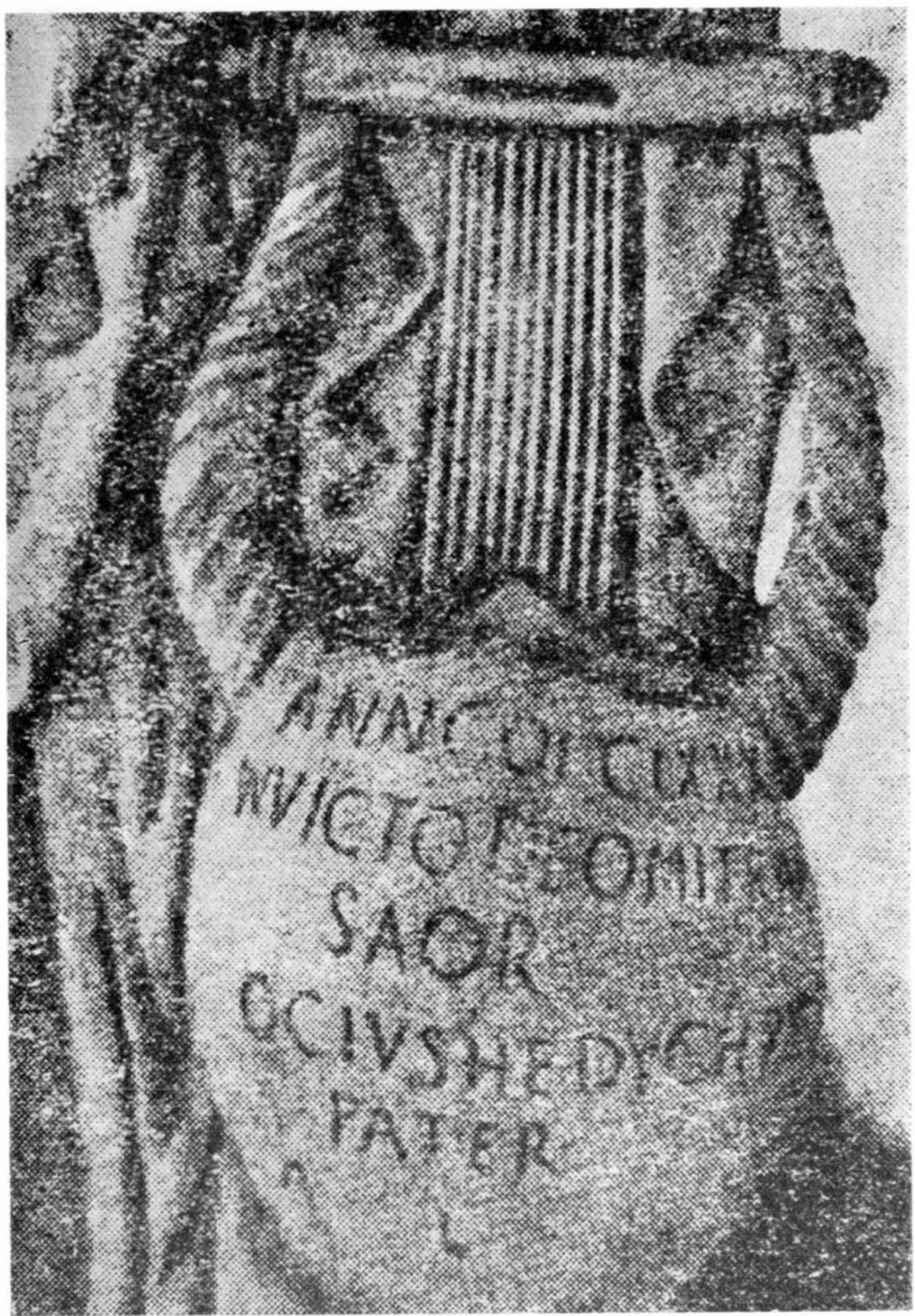

Figura 11. Lira de diez cuerdas de una estatua de Mercurio hallada en Mérida, España. 
DOI: http://dx.doi.org/10.22201/iie.18703062e.1977.47.1082

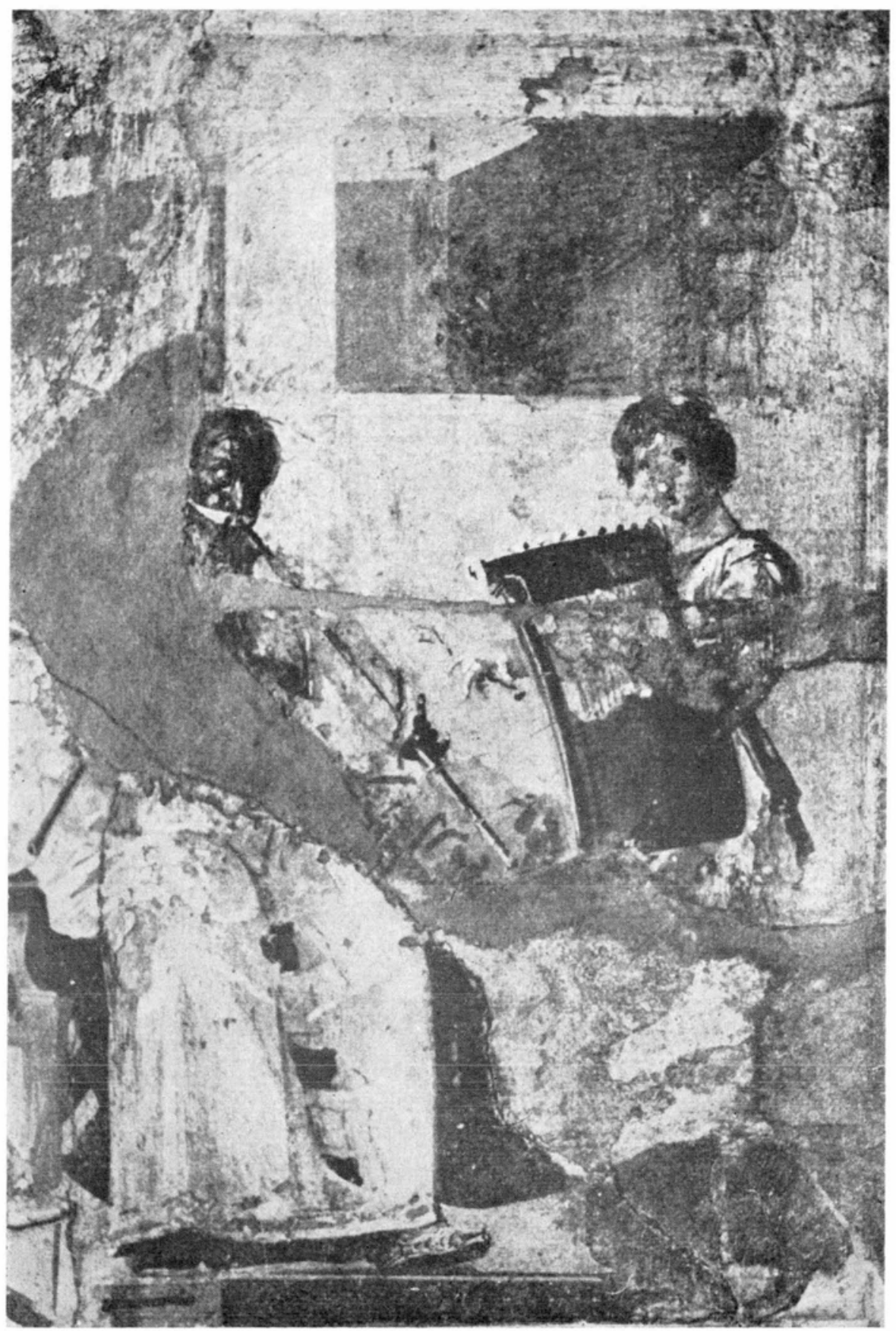

Figura 12. Fresco hallado en Herculano (Museo Arqueológico de Nápoles). 


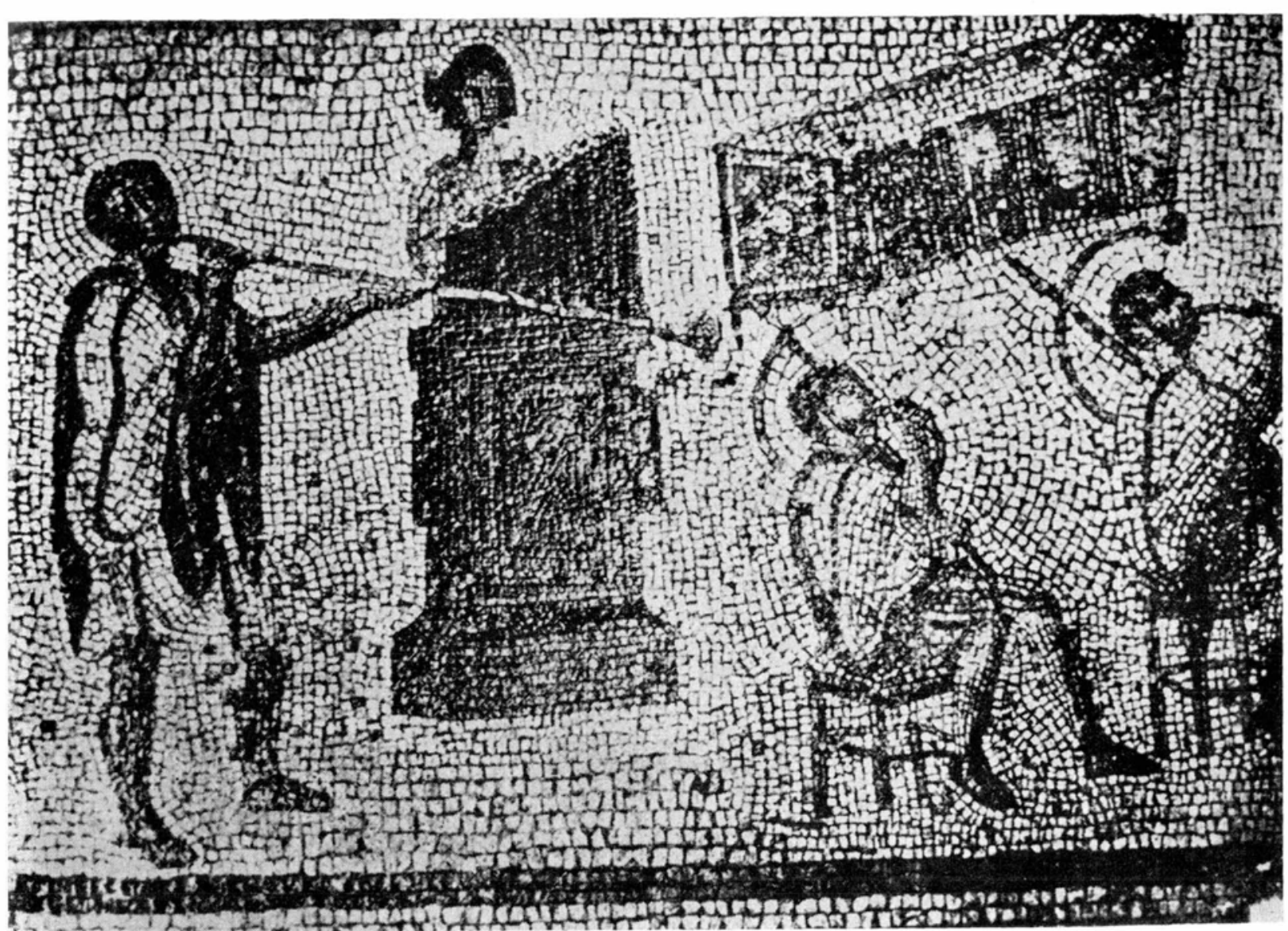

Figura 13. Mosaico que representa músicos en el circo. La banda toca tuba hydraulus y cornus (c. 20 a. C.). 
DOI: http://dx.doi.org/10.22201/iie.18703062e.1977.47.1082

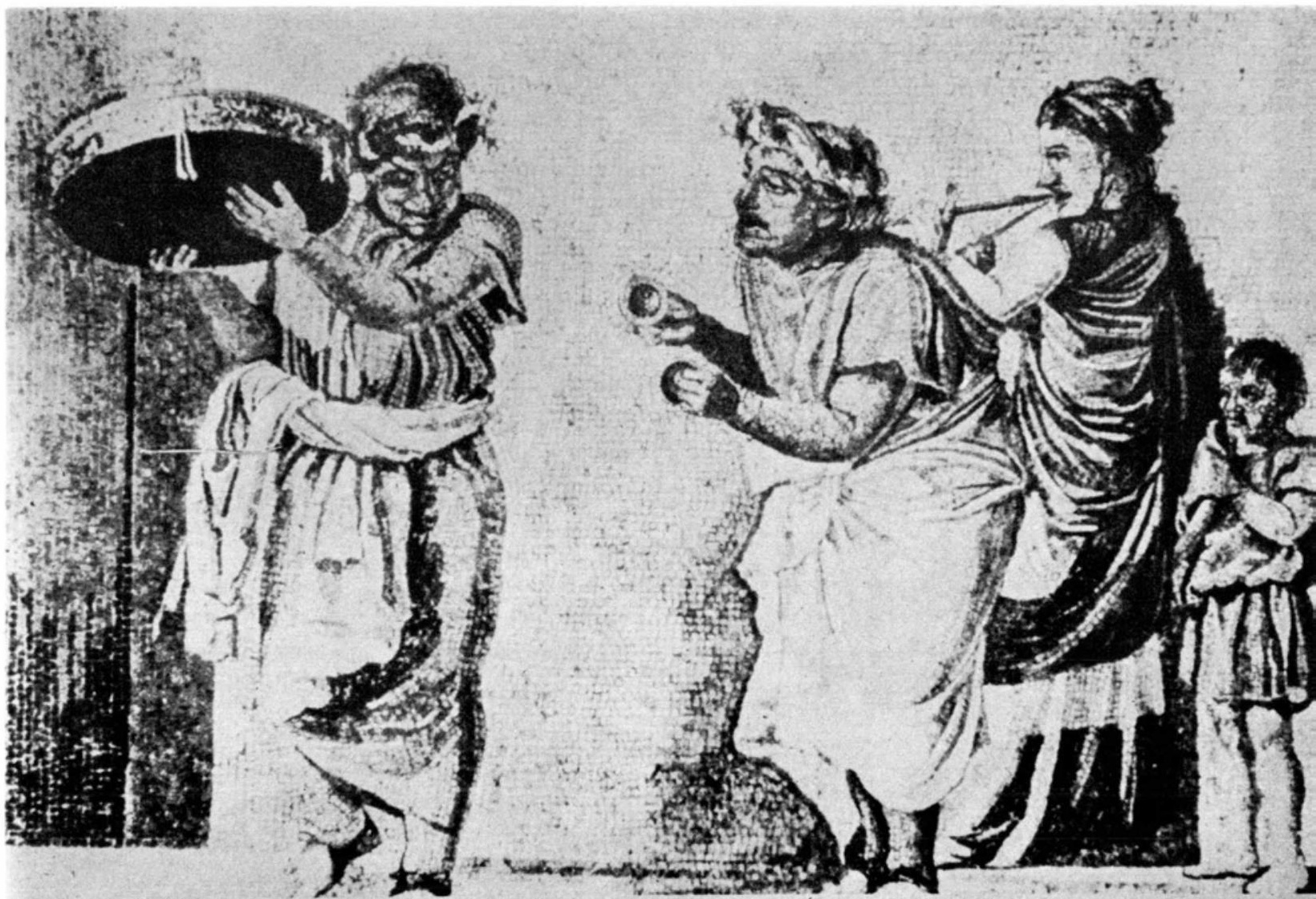

Figura 14. Mosaico hallado en Pompeya, representa músicos callejeros y está firmado por un artista neoático (Museo Arqueológico de Nápoles). 
DOI: http://dx.doi.org/10.22201/iie.18703062e.1977.47.1082

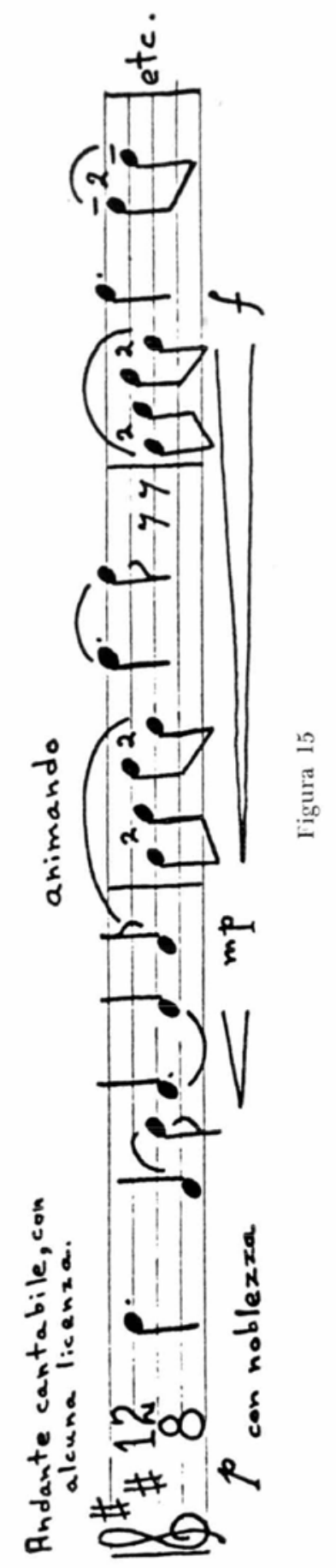


DOI: http://dx.doi.org/10.22201/iie.18703062e.1977.47.1082 
una inscripción que ha permitido atribuirle la fecha del $228 \mathrm{~d}$. C. y consta de cuatro filas de tubos, con trece flautas en cada una y restos de elevadores, apagadores y un teclado de control manual (figura 7).

El órgano tubular, invento romano, ha sido uno de los instrumentos más consistentes, duraderos e importantes de nuestra civilización. La técnica ha electrificado sus mandos, ha obtenido fuelles de acción eléctrica y ha sofisticado el uso de registros acústicos; pero no ha modificado la base del hydraulus romano, el cual tenía ya las posibilidades polifónicas del órgano moderno al par que un sistema para variar sus registros (figura 8).

El hermoso y poético instrumento hallado en Aquincum tiene por lo menos 16,000 posibilidades distintas de obtener diversas posiciones fónicas en sus tubos. Era un instrumento pequeño, apto para ser usado en la intimidad, en pequeñas reuniones familiares o agasajos - tal vez para entretener a los comensales de una taberna. Un instrumento reconstruido, que puede ser tocado, permite oír la hermosa voz del aparato, cuyo registro de dos octavas admite algunas delicadezas polifónicas y armónicas. Cada uno de los cuatro órdenes de tubos tiene una voz marcada. mente característica y es posible en virtud de sus sonidos fundamentales, tocar a la tercera, a la quinta y a la octava. De suyo, el descubrimiento del instrumento permite afirmar la posibilidad de que la música romana haya conocido las consonancias medievales, tan caras al oído convencional del siglo $\mathrm{xx}$.

Una placa de bronce hallada con el hydraulus dice:

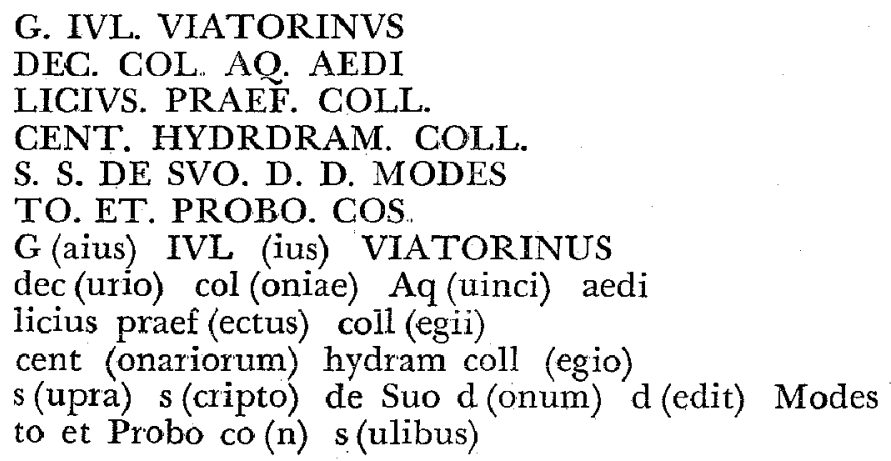

El regalo del señor Viatorinus no fue sólo a Aquincum sino a la posteridad. Justo es guardarle un lugarcito en la historia, a cambio de tan espléndida donación. 
El más bello dato que la investigación del hydraulus de Aquincum permite recabar es que se trata de un instrumento cromático, un instrumento de teclado cromático de los romanos, tan moderno y con tantos recursos musicales básicos como cualquier instrumento del mismo tamaño que pueda hacer la tecnología del siglo xx (figura 9).

Los hydraulus gigantes que se usaban en Roma y las grandes ciudades deben haber tenido todo recurso tímbrico posible, en virtud de que sus cuatro órdenes de tubos de alma, de madera, de lengüeta y el flautado otorgan riquísimas posibilidades.

El syring griego era usado más bien por los pastores y no parece haber tenido lugar en la música profesional. Doce flautillas de diverso tamaño se juntaban y se pegaban con cera, el ejecutante soplaba y movía el instrumento con las manos para obtener los sonidos deseados. El caramillo de los escasos afiladores callejeros que a veces ejercen su oficio, en vías de extinción, en la ciudad de México, es un descendiente directo de estos instrumentos (figura 10 ).

Los instrumentos de percusión eran muchos y su importancia grande a causa del énfasis romano en el ritmo. Los más importantes y los más conocidos eran el scabellum, que consistia en un soporte con bisagras que detenía un cuadro de madera o metal que giraba y se accionaba con el pie, tal vez para batir el tiempo golpeando en el marco.

El sesset egipcio, que los griegos bautizaron como seistron y los romanos como sistrum es un instrumento de la más remota antigüedad. Herodoto comenta que "los egipcios fueron los primeros en usar asambleas solemnes, procesiones y letanías a los dioses, todo lo cual aprendieron los gxiegos de ellos". E1 conocimiento posterior sugiere un posible origen mesopotamio de tales instituciones, pero el sistrum fue aceptado en el mundo romano como un instrumento de origen egipcio transmitido por los griegos y vinculado al culto de Isis. En el siglo III a. C. la difusión del culto de Isis y Serapis era grande en Grecia y su extensión a Roma motivó censuras del poeta Tibullus (c. 54-19 a. C.) hacia el instrumento extranjero. El sistrum era un pequeño aro de metal que se acoplaba a un dedo y se golpeaba con otro. Había también diversas clases de platillos, campanas, silbatos y panderos.

La lira $(\lambda v \varrho \alpha)$ griega y la kithara romana eran instrumentos diversos. En Roma la lira se extinguió y la kithara adquirió más cuerdas, la caja de resonancia se amplió y se hizo menos manuable. A menudo se tocaba sentado y hasta el fin del Imperio fue el más importante instrumento para los solistas. Las arpas, que fueron tan bien difundidas 
entre asirios, caldeos, egipcios y griegos alcanzaron una inmensa popularidad en Roma. Se tocaban con el ejecutante sentado que mantenía el instrumento sobre sus rodillas. La pandura fue un peculiar instrumento de cuerda que tenía un largo diapasón y trastes en el mismo. Era de origen oriental y su caja de resonancia era corta y ovalada, hecha de piel sobre un marco de madera perforado por un agujero grande y varios más pequeños alrededor. Las cuerdas no estaban enrolladas en clavijas sino en lengüetas de metal (adornadas con borlas) que podían moverse permitiendo su afinación (figura 11).

Existen descripciones literarias de instrumentos, hechas por poetas - escritores cuyos conocimientos musicales no permitían una precisa descripción técnica. La más bella, y la más precisa, describe una tibia: "Un viento, dos barcos, diez marineros xemando y un timonel que dirige a ambos." 3

Música y vïda, conciertos, espectáculos y guerra

La vida cotidiana usaba mucho de la música. Marcial pensaba que la mejor diversión se obtenia cuando no había un flautista que ahogara la conversación, sino cuando la música se of́a después de comer. Desde los más remotos tiempos romanos se empleó la música en los funerales. Ya en el Imperio no se concebía un funeral sin flautistas y trompetas que dieran un último concierto al difunto. Trimalquio, ya muy borracho, ordena en una orgía un funeral satírico y los trompeteros tocan una marcha fúnebre. La frase: "Puedes llamar a los trompeteros" (ad tubicines mittas), implica la idea de prepararse para un entierro. Después de la cena en la villa de Plinio se oía un poco de música ligera. En la ruidosa orgía de Trimalquio se escuchaba una fuerte trompeta.

Había conciertos en las casas de los romanos ricos. Un fresco de Herculano, ahora en el Museo Arqueológico de Nápoles, muestra a un flautista y un kitharoedus que tocan en uno de estos conciertos privados. Se llegaba al exceso, ya que Petronio cuenta de un señorito que tenía un reloj en el comedox y un bucinator uniformado junto al reloj, que mediante su música le informaba cuánto de su vida se había ido y estaba ya perdido. Además, pequeñas bandas de músicos callejeros recorrían Roma tocando flautas, platillos y pandereta (figura 12).

Desde el siglo m a. C. actores etruscos llevaron a Roma obras teatrales con acompañamiento músical en las que se bailaba al son de música tocada por flautas. Después de recibir la influencia del teatro griego,

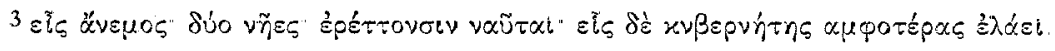


ese antecedente fue la base histórica del pantomimus, que versaba sobre temas mitológicos y esencialmente consistía en una danza teatral para un solo ejecutante acompañado de coro y orquesta. Los actores solían ser romanos y no fue sino hasta el siglo in $d$. C. cuando principiaron a admitirse actrices en el espectáculo. La orquesta estaba compuesta de tibii, caramillos, platillos, kithara, arpas y scabellum, que en esta clase de arte tendría, tal vez, un papel preponderante. Había que tener un gusto educado para gozar del pantomimus: era preciso conocer los detalles del argumento y reconocer los distintos pasos y posiciones de la danza, por lo que no llegó a ser un espectáculo de masas. Plutarco da fe de que dentro del pantomimus reinaba el arte de la danza, al cual estaba la música casi completamente subordinada.

El drama griego recibió una gran cantidad de música en sus versiones latinas. Los prefacios a las obras de Terencio hablan de cuatro diferentes clases de flautas para usar en diversa música y dan el nombre del compositor de la misma. Durante los intermedios se tocaba música. En un texto del siglo In o principio del I a. C. se hallaron indicaciones para el uso de música en una obra teatral. La identificación de las señales no se precisa, pero se han podido reconocer las entradas de tambores (una vez, cinco veces, o con un número superior indeterminado de toques), la percusión de algún instrumento que podría ser unos platillos o el scabellum y otras dos señales que posiblemente cran para castañuelas y flauta. Infortunadamente, sólo son señales que ordenan el uso de música en esos sitios pero no hay el menor rastro de la música que debía sonar.

Dionisio de Halicarnaso observa que en una representación del Orestes de Eurípides durante el imperio de Augusto, la música no enfatiza los acentos del texto y añade que en dos versos! pareados, estrofa y antiestrofa, la melodía debía ser idéntica. Esto implica que los romanos usaban seguir los desniveles de la entonación y los acentos métricos con acentos musicales.

Un espectáculo en el anfiteatro principiaba con un desfile encabezado por trompetas y cornos ante los participantes, que marchaban en la arena con cascos ricamente ornamentados. El inicio del juego era anunciado por la tuba y una pequeña orquesta tocaba en los descansos y tal vez como fondo. Se conocen mosaicos en donde aparecen distintos tipos de gladiadores y, entre ellos, una orquesta formada de hydraulus, tuba y dos cornicines con sus respectivos instrumentos (figura 13). 
El interés por la música no implicaba la aceptación social del músico en calidad distinguida. A pesar de la afición musical de muchos patricios y de algunos emperadores, el músico profesional era considerado indigno de alternar igualitariamente con la aristocracia. E1 horror social que causaron las inclinaciones musicales de Nerón no fue condicionado por sus apariciones como músico, sino por el hecho de que deseara considerarse un artista profesional y se presentara como tal (figura14).

"La música que aún no suena es mejor que la que se ha oído", decian los antiguos griegos; pero Nerón, se dice, replicaba: "La música que aún no suena es inconcebible."

Ninguna mujer decente tocaba un instrumento musical demasiado bien, ningún patricio ortodoxo bailaba a menos que estuviera tomado y un emperador con aficiones musicales era considerado una calamidad social; sin embargo, las aficiones musicales imperiales no faltaron jamás. Adriano se jactaba públicamente de su alto nivel de eficiencia como cantante y ejecutante de kithara. Verus viajó a Corinto y Atenas con cantantes e instrumentistas, y a su regreso de la guerra con los partos trajo de Siria flautistas y ejecutantes de instrumentos de cuerda como un precioso botín de guerra. Cómodo fue criticado por su afición al arte de cantar, nada correcta para un emperador romano. Heliogábalo declamaba acompañado de la tibia, cantaba, bailaba y tocaba (se dice que muy eficazmente ctal vez con la eficiencia que los políticos inmensamente poderosos tienen en todo lo que hacen?), que era capaz de ejecutar la tuba, la pandura y el hydraulus. Alejandro Severo tocaba la lira, la tibia, el hydraulus y la tuba, si bien renunció a esta última cuando fue emperador por considerarla incompatible con la dignidad imperial.

El emperador estrella en el área fue Nerón, quien, al parecer, deseaba que se le tomara muy en serio como músico. Los testimonios y, en un cierto grado, la propia intensa afición del imperator dan fe de su habilidad musical basada casi ciertamente en un seguro instinto artístico. Estudiaba seria y arduamente. Empleó a un famoso cantante y ejecutante de kithara, Terpnus, para que le diera clases y trabajaba en ello hasta muy tarde. Se esforzó en todo sentido y se acostaba con un pesado cofre de metal sobre el pecho, tomaba purgas, se abstenía de algunas frutas y de carne, que se suponía dañaban la voz, y acudía a todos los trucos que los profesionales conocian o que su maestro inventaba para desarrollar la voz En alguna ocasión provocó un conflicto político cuando se negó a arengar a sus soldados por temor a dañarse la voz; 
tenía un profesor de canto casi constantemente a su lado para vigilar que su hermosa voz no fuera sometida a esfuerzos extraordinarios. Antes de una de sus apariciones públicas como músico elaboró detallados planes para el uso de una claque de 6,000 personas, que debería dividirse en multitud de grupos pequeños y asegurar el éxito de su amo. La claque del emperador fue instruida en las diversas clases de aplauso que deberían emplear - se sabe de tres tipos de intensidad logarítmicamente ascendente: bombi, testae e imbrices, este último era un clamor desenfrenado. El emperador era muy celoso de sus rivales (políticos o musicales) y extremadamente sensible acerca de su reputación artística. Cuando afrontó la rebelión de Vindex lo que más Io irritó y exasperó no fue la actitud política del rebelde, sino la baja opinión de Vindex acerca de su capacidad para tocar la kithara.

Nerón principió su carrera musical a los veintidós años, en un concierto que tuvo lugar en su propio palacio, en el 59 d. C. En 64 participó en los concursos profesionales de Nápoles y en 65 se presentó como kitharoedus en el Teatro de Pompeyo de Roma. En 66 fue a Grecia para realizar una gira de conciertos en plan profesional, de la cual volvió en 68 , haciendo pública ostentación de sus triunfos. Tal vez los jueces de los concursos estimaron poco saludable y antiproffiláctico negar premios al emperador, pero el interés musical de Nerón resultaba muy claro. Sabemos que observaba las reglas, adoptaba una actitud de subordinación artística $y$, por lo menos una vez, estaba nervioso y preocupado ante la posibilidad de que un error bajara su puntuación en un concurso.

Además de los emperadores, había ciudadanos que desahogaban su excentricidad por caminos musicales. La extravagancia romana se expresó bien en la música. Ammianus Marcellinus cuenta de kitharae tan grandes como carros de batalla en el 284 d. C.; Carinus ofreció una serie de juegos a los romanos, en los que 100 tubae tocaron juntas -entre los músicos que participaron había 100 cornicines (con sus instrumentos, naturalmente) y 200 täbiae, que también actuaron a la vez- fue el acontecimiento del año y las autoridades romanas alentaron esta manía por la novedad y la extravagancia musical -y de otras clases, algunas más siniestras- en cumplimiento del panem et circens, tan eficaz para alejar a las masas de inútiles inquietudes políticas.

La música era capital en el ejército romano, ya que las órdenes militares se impartían, en muchos casos, mediante toques de diversos instru- 
mentos "La tuba tocaba al ataque o retirada y también se usaba para indicar el momento del cambio de la guardia. La bucina, cuyo volumen más débil no le permitía ser oída fuera de los campamentos si había ruido, señalaba las horas de vigilia de la guardia; posteriormente fue sustituida por el cornu con el que también se ordenaba el relevo de los centinelas. Pollux relata de cuatro señales para la tuba: la de ataque, la de aliento durante la batalla, la de retirada y la usada para detenerse, también empleada - con una modificación- para acampar. En el siglo vi d. C. Procopio señalaba que el ejército romano de los viejos tiempos tenía dos toques: la carga y la retirada, e indica que alguna vez deben haberse confundido, pues Ios hacía el mismo instrumento. Esto sirve para aconsejar a Belisario que la trompeta de caballería, más liviana, fuera hecha de piel y madera para que señalara la carga y que la pesada trompeta de bronce de la infantería debería ser usada para la retirada, ya que su sonido distinto, más fuerte y menos agudo, sería mejor percibido entre el clamor y el estruendo de la batalla.

Hay varios relatos acerca del truco musical empleado por los generales romanos para engañar al enemigo, que consistía en dejar a los músicos en el campamento cuando éste había sido abandonado, con el objeto de que continuaran sonando sus toques regulares e indujeran al error a los contrincantes. A veces, un trompetero exa enviado lejos del cuerpo del ejército con el objeto de dar una impresión falsa de la posición de las legiones. Existen diversos modismos que revelan la fuerte identificación de los toques musicales con la vida militar: in medias tubae se traduce como "enmedio de la batalla" y post lituos indica "después que la batalla ha terminado". En el campamento y durante la marcha el cornu daba la señal de desalojar y la tuba llamaba a redoblar la lucha en la batalla. Cuando el Templo del Sol de Palmira fue saqueado en 272 d. C. por los aquiliferi, vexilliferi y draconarius de Aureliano, los músicos legionarios que tocaban cornu y lituus también participaron en el pillaje.

El 23 de marzo y el 23 de mayo, en una solemne ceremonia, el $t u b i$ lustrium, las trompetas sagradas eran simbólicamente purificadas, en un ritual que se cree conectado con el inicio anual de las campañas. Lo importante es que muestra muy claramente la íntima conjunción del instrumento musical con la vida militar. En la marina, las necesidades de llamadas audibles eran mucho menores, pero se sabe que se utilizaba música para señalar el ritmo de los remeros. A pesar de que la tuba fue completamente aceptada en la vida civil, y de que se usaba 
con otros instrumentos, su relación con la vida militar no se olvidó, ya que Casio Dio relata que cuando L. Norbanus Flaccus, que era un hábil intérprete de $t u b a$, fue oído practicando el día en que su periodo consular comenzaba, en el 19 d. C., se tomó como un mal augurio el que se oyera al nuevo cónsul tocando un instrumento asociado con la guerra.

La música es la más frágil de todas las estructuras culturales. Depende tanto de la tradición y de los usos no escritos que se transforma continuamente y sus estilos perecen con las épocas que les dan origen. Tan pronto mueren los que la hacen y la viven, el estilo propio de quienes la inventaron se desbarata ya que un concepto no tiene cuerpo material y fuera de los cerebros que lo piensan carecen de existencia propia. Los sistemas de notación dependen tanto de aquellos que los utilizan, que una vez extintos los hombres el sistema cae en lo ignoto. Así se perdió el tesoro de la música mozárabe, de la cual existen muchos libros cuya notación es indescifrable y cuya clave está perdida. Al no ser trąnscritos a la notación diastemática por lo monjes que pudieran hacerlo, esa música falleció con la muerte de la música bizantina, cuya notación ekfonética está sólo parcialmente descifrada y que tan violentas controversias interpretativas desata entre los especialistas. Cuando Isidoro de Sevilla, que no conocía los sistemas modernos de notación musical, dijo en el siglo vir que "a menos que los sonidos sean xetenidos. por la memoria del hombre, perecen, pues ellos no pueden ser escritos", tocó un fondo más profundo de lo que el especialista obtuso desea cómodamente admitir. Isidoro conoció algún sistema de notación; pero la música depende tanto de los seres vivos que la practican que, aún anotada, desaparece con ellos, ya que una gran cantidad de elementos que le dan vida y agilidad nunca son escritos. Las controversias acerca de la interpretación de la música de los siglos xvir y xvir es particularmente expresiva al respecto, ya que al morir los músicos barrocos desaparecieron los conocimientos precisos que regían el estilo de ejecución de su música. Parte se conserva, pero el sistema exacto y completo no se conoce - pese a la inútil actitud de musicólogos pedantes que a veces no tienen empacho en inventar la información o en extendex, por analogía, a todo el sistema estilístico barroco, instituciones que sólo pueden válidamente aplicarse a secciones bien definidas del mismo. Aun en 
pleno siglo $\mathrm{xx}$, ya cercanos al $\mathrm{xxr}$, con el hombre lanzado al espacio $\mathrm{y}$ con máquinas que amplifican el poder de la mente, tanto o más de lo que los instrumentos amplian el del cuerpo, parte de la tradición estilística de nuestra era perecerá, pues no está escrita -a pesar de que ahora las grabaciones, representaciones ideales, algo equívocas y monstruosamente momificadas de la realidad instrumental, prestan un servicio que Isidoro de Sevilla tal vez jamás llegó a concebir. Tomemos tan sólo un punto de ejemplificación: el vibrato en los instrumentos de cuerdas. En el siglo XIx se tocaba, en general, sin vibrato y todavía violinistas muy ancianos tocan así, en la vieja escuela en que aprendieron. Actualmente, el conocimiento y dominio de las diversas clases de vibrato es fundamental en todo instrumentista de cuerda. La aplicación adecuada de un vibrato más o menos rápido y más o menos amplio a diversos pasajes, según se requiera, es timbre de orgullo en solistas y conjuntos de toda clase. ¿Qué director se atrevería a que los violines primeros y las violas de su orquesta tocaran el segundo tema del segundo movimiento de la Quinta Sinfonia de Chaikovski sin vibrato? (figura 15). Sería apedreado por sus músicos. Y si éstos hicieran un vibrato demasiado lento o excesivamente amplio tal vez un director irascible intentaría ahorcarlos. $\mathrm{Y}$ ¿dónde está escrito ésto? Es un conocimiento universalmente aceptado que no está sistematizado en texto alguno. Es una característica tan sutil, tradicional y dependiente de la moda y la cultura moderna que tal vez no pueda ser escrita con precisión, ya que pertenece a la esfera del instituto profesional más estrechamente vinculado con la tradición oral y con el área típica y propia de esta cultura, que morirá con ella.

Por esto es que la música romana es un arcano que tal vez no sea jamás develado, a menos que concepciones tecnológicas tan fantásticas como la máquina del tiempo de Wells sean algún día realidad. Las posibilidades de ejecución de los instrumentos tampoco permiten afirmar con cexteza el conocimiento del sistema de ejecución, ni de la música, ni del uso que de ellos se hacía. El que un artefacto pueda producir tal o cual sonido, o sea capaz de permitir un determinado efecto, de ningún modo convalida la afirmación de que esos sonidos y esos efectos eran el patrimonio diario y común del sistema musical al que pertenecen. El violín puede producir sonidos continuos similares al de una sirena, pero no podemos decir que la música de los siglos xvir, xvin y xix conste de tales sonidos. 
Debemos, por lo tanto, dejar a la música de Roma envuelta en la bruma de misterio con que los siglos y la caída del Imperio Romano la han cubierto. Los romanos muertos guardan púdica y celosamente algunos de sus misterios, a salvo de miradas curiosas y de intrusos poco respetuosos. Algo de la poesía del pasado está en la borrosidad de algunas de sus partes; en ocasiones, cuanto más borroso, poco delineado y preciso es, algo tanto más intrigante y poética es. $\mathrm{Y}$ así es la música romana, como tantas otras añoranzas de aquel mundo perdido, que alguna vez poseyó todo el esplendor que los humanos pueden concebir, y que 2,000 años después todavía reverenciamos y admiramos como a ningún otro que jamás haya existido.

\section{BIBLIOGRAFIA}

Aberr, A, en Friedländer: Darstellungen aus der Sittengeschichte Roms, Leipzig, 1921.

Amiano, Marcelino. Historia del Imperio Romano. Trad. de Nobexto Castilla. Madrid. 1885-1892.

Ateneo de Naucratis. Los Deipnosofistas (The Deipnosophists). Trad. de C. B. Gulick. Loeb Classical Library. 1950

BaIHolinus. De tibiis veterum et earum antiquo usu libri tres. Roma. 1677.

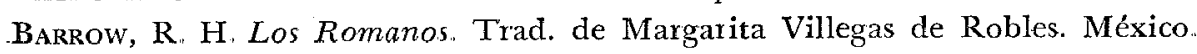
1950.

BEHN, F. "Die Musik im römischen Heere" Mainzer Zeitschrift VII. Mainz. 1912.

-_- Musikleben in Alierium und frïhen Mittelalter. Stuttgart. 1054.

BIEBer, Margarete. Die Denkmaeker zum Theaterwessen im Altertum. Berlin. 1920 .

. The History of the Greek and Roman Theater. Princeton. 1939.

Cicerón. Leyes "De legibus. Trad. de E. W. Keys. Loeb Classical Library. 1942.

Chappeld, W. History of Music. I. (From the earliest records to The fall of the Roman Empire). Londres. 1874.

Degañ. La Musica nella preistoria e nelle antiche civiltà . Reggio Emilia. 1939. Dron, Cassius Historia Romana. Trad de M. Gros "Paris 1846. 7 vols.

Du Tilizot. Mémoîres pour servir a lhistoire de la fête de fous. Ginebra. 1751. Frank, Tenney. Economic Survey of Rome. New York. s. f.

FELL, R. A. L. Etruria and Rome. Cambridge. 1924.

Geroln, Théodore. Histoire de la Musique des origines a la fin du XIV siècle. Paris. 1936. 
Gevaert, Fr. A. Histoire et théorie de la musique de L'Antiquité. Gante. 18651881.

Giglioli, G. Q. L'Arte etrusca. Milán. 1935.

Goerz, Walter. Historia Universal, t. II. "Hélade y Roma". Trad de Manuel García Morente Madrid. 1933.

Gombosi, O. Tonarten und Stimmungen der antiken Musik. Copenhagen. 1939"

Horacio. Odas. Trad de P. Urbano Campos. Madrid. 1783.

Jones, A. H. M. Catalogue of the Ancient Sculptures preserved in the Municipal Collections of Rome. "Palazzo dei Conservatori." Oxford. 1926.

_._-_._. Ibidem." "Museo Capitolino" Oxford. 1912.

---D- The Greek City from Alexander to Justinian. Oxford. 1940.

KabA, Melinda y Pécsi, Sebestyén. Az Aquincumi Orgona. Budapest. 1975.

Kuszinsky, V. Aquincum. Budapest. 1934.

LA PIANa, G. "Foreign groups in Rome during the first centuries of the Empire". Harvard Theological Review. 1927, vol. xx.

LAST, H. "The Servian Reforms". Journal of Roman Studies. 1945, vol. xxxv.

Léo, Federico. Literatura Romana. Trad y notas de P. U. González de la Calle. Bogotá. 1950.

Luciano. Sobre la danza (Peri Ockheseoos). A. W. Harved. 1936, vol. v.

Macaulay, Thomas Babington. Lays of Ancient Rome, Leipzig. 1851.

Mc Cartney, E. S. "Military indebtedness of Early Rome to Etruria". Memoirs of the American Academy in Rome. I. Roma. s. $\mathrm{f}$.

Mercureilr, C Revista di Archeologia cristiana. Roma. 1938.

Millares Carlo, Agurtín. Historia de la literatura latina. Fondo de Cultura Económica. México. 1950.

Mommsen, Théodore. Römische Geschichte (1851-66). Trad. inglesa de W. P. Dickson. Londres y Nueva York. 1931, 4 vols.

Mostra Augustea della Romanita. "Catálogo, Índice y Bibliografía." Roma, 1939 (la sección Lxx se refiere a música).

Nagy, L. Die Orgel von Aquincum. Budapest. 1934.

Ovidio. Heroidas y Amores "Trad. de Grant Showrmann. The Loeb Glassical Library. 1931.

Paribeni, R. "Cantores Graeci nell'ultimo secolo della repubblica in Roma". Raccolta di scritti in onore di Giocomo Lumbroso. Milán. 1925.

Pickard-Cambrige, A W. The Dramatic Festivals of Athens Oxford. 1953. Poliux. Onomasticon. Ed. Wetstein. Amsterdam. 1706, 2 vols.

Reinach, S Répertoire des reliefs grecs et romains. Paris. 1909.

-_- Répertoire des peintures grecques et romains. Paris. 1922.

Rizzo, G. E. La pittura ellenistico-romana. Milán. 1929.

Ruelle, Ch. Em. Le Musicographe Aristide Quintïlien. SIMG, Leipzig 1890. 
SAlazAr, Adolfo. Teoria y práctica de la música a través de la historia, t. II. "La era Monódica en Oriente y Occidente." I. Roma. México. 1958.

Scotr, J .E. "Roman Music" The New Oxford History of Music (Ancient and Oriental Music). Londres. 1957, vol. I.

SolARI, A. Vita pubblica e privata degli Etruschi. Florencia. 1931.

Strong, E. La scultura romana da Augusto a Costantino. Florencia 1923. - Art in Acient Rome. Londres. 1929.

Suetonio. "Vida de Calígula". De Vita Caesarum.

_-__. "Vida de Nerón". De Vita Caesarum. "Vida de Tito". De Vita Caesarum. Trad. de H. Ailloud. Col. Budé, Paris. 1931-32.

TÁcito. Historias y Anales. Trad. de C. H. More y J. Jackson, Loeb Classical Library, 4 vols.

Taubenschlag, A. Law of Greco-Roman Egypt in the light of the papyri. New York. 1944.

Wallace, E. Taxation in Egypt. Pxinceton. 1938.

Zrelinskr, T. Historia de la civilización antigua. Trad. de Carlos Pereyra. Madrid. 1950. 